\title{
Adolescents' Knowledge and Attitude towards Regular Healthcare as a Way of Improving HIV/STD Testing and Treatment
}

\author{
Rita Nkiruka Ezeokoli ${ }^{1}$, Kolawole Olanrewaju Ayodele $^{2} \&$ Yemisi Lydia Olaleye $^{3}$ \\ ${ }^{1}$ Department of Social Work, Babcock University, Ilishan-Remo Ogun State, Nigeria \\ ${ }^{2}$ Research and International Cooperation, Babcock University, Ilishan-Remo Ogun State, Nigeria \\ ${ }^{3}$ Department of Social Work, University of Ibadan, Oyo State, Nigeria \\ Correspondence: Kolawole Olanrewaju Ayodele, Research and International Cooperation, Babcock University, \\ Ilishan-Remo Ogun State, Nigeria. E-mail: ayodelewole@gmail.com
}

Received: May 28, 2014

doi:10.5539/ijps.v6n3p44
Accepted: July 14, $2014 \quad$ Online Published: July 30, 2014

URL: http://dx.doi.org/10.5539/ijps.v6n3p44

\begin{abstract}
This study examined the adolescents' knowledge and attitude towards regular healthcare as a way of improving HIV/STDs testing and treatment among secondary school students in Oyo State, Nigeria. This study employed the descriptive research design type. Two hundred and twenty participants selected through multi-stage stratified random sampling technique were used for the study. One main instrument was used in collecting data. Data was analyzed using Pearson Product Moment Correlation Coefficient and T-test. Results showed a significant relationship between students' knowledge and attitude to regular healthcare on the testing and treatment of HIV/STDs. Also, a significant difference in the knowledge while no significant difference was found in the attitude of regular healthcare as a factor in the testing and treatment of HIV/STDs among private and public secondary schools' students. A gender difference in attitude toward regular healthcare was observed but not in knowledge. Also, no significant differences were found in the knowledge and attitude towards HIV/STDs Testing and Treatment of single parenting and intact home (both parents) respondents. On the basis of the findings, it was established that while the majority of secondary students had heard about HIV/STDs, their knowledge was inadequate. Thus, schools have a role to play in facilitating the access of young people to necessary reproductive health services and to link education and services so that students may bridge knowledge and attitudes with action.
\end{abstract}

Keywords: adolescents, knowledge, attitude, regular healthcare, HIV/STD, secondary school students, Oyo State, Nigeria

\section{Introduction}

Sexually Transmitted Diseases (STDs) according to F. Zeeb, Spallenek and H. Zeeb (2011) are major health problems affecting mostly young people not only in developing, but also in developed countries. Human Immunodeficiency Virus (HIV) on the other hand has been described as the pandemic of our time and has been receiving a lot of attention worldwide. Globally, 33.2 million people were estimated to be living with HIV and 2.5 million were newly infected with HIV in 2007 (WHO, 2008). As the HIV epidemic spreads, younger age groups are becoming exposed to the risk of infection (UNAIDS, 1999). Ten million youth (ages 15-24) worldwide are living with HIV and every day, an estimated 6,000 youth are infected with the virus. Although they could be found in countries on all continents, most of them lived in sub-Saharan Africa (UNFPA, 2005).

The $2008 \mathrm{HIV} /$ Syphilis Sentinel Survey in Nigeria revealed that 3.3\% of young people aged $15-19$ are infected with the HIV virus (Federal Ministry of Health, Nigeria, 2008). Sexual intercourse is the most predominant mode of transmission of HIV in sub-Saharan Africa, accounting for approximately $90 \%$ of all infections (De Kock, Ekpini, \& Gnaore, 1994). Young people are particularly vulnerable to HIV and STD infection because of the physical, psychological, social and economic attributes of adolescence (Earl, 1995) and are also at risk due to the high levels of risky sexual behaviours and the attitudes, expectations and limitations of the societies in which they grow up (Population Reference Bureau, 2000).

Adolescents are known to be adventurous groups; and indulge in sexual activities just for the reason of experimentation and peer influences, owing to a wealth of uncensored information they are exposed to, through 
an intensifying wave of westernization, the internet, and electronic media, Coupled with a shallow knowledge and nonchalant attitude about the dreaded HIV virus and STD infections. These risky behaviours predispose adolescents to the risk of HIV/STD infections. Several studies have reported high rates of pre-marital sexual activities among Nigerian adolescents (Feyisetan \& Pebley, 1989) over 16\% of teenage females reported first sexual intercourse by age 18 . Studies have shown that, adolescents who begin sexual activity early are likely to have sex with more partners, and with partners who have been at risk of STD and HIV exposure (WHO, 2002). Thus, a major goal of HIV and STD prevention programs is to delay sexual debut.

Actions taken during adolescence can affect a person's life opportunities, behavioural patterns and health. AIDS is a disease that can damage any of the body's major organ systems because HIV destroys immune system cells. Because the immune system cells are destroyed, a wide variety of infections and cancers can take advantage of a person's weakened immune system (opportunistic infections/diseases) (Aids Info, 2009). Although they are usually not fatal, sexually transmitted diseases (STDs) can lead to major pregnancy complications, secondary infertility and severe discomfort. Moreover, STDs have been identified as a predisposing factor in the transmission of HIV (Laga, 1992).

According to United Nations Population Fund (UNFPA, 2013), regular healthcare is a right for everyone including adolescents. When adolescents avail themselves for healthcare services regularly, they are better able to protect themselves against STDs, and HIV. The delivery of quality healthcare services can have a large impact on the health of Nigerians including the adolescence. Most of the cost- effective health interventions to prevent HIV and treat STDs in adolescence are a progress towards the health Millennium Development Goals (MDGs).

With more children than ever receiving education, schools are effective way of reaching school-age youths in an organized way, on enlightenment programme on HIV/STD programmes, to broaden their knowledge and attitude to these life threatening infections. The promotion of children's healthcare through schools is being recognized globally as an important means of influencing health behavior. It has been an important goal of WHO, UNESCO, UNICEF, and other international agencies for more than 40years-a goal which have gained significant momentum in recent years (Birdthistle \&Whiteman, 2012).

Prevention of STDs and HIV pose a great challenge to nations of the world in general and to Nigeria in particular. Alutu (2002) claims that this challenge stems from the fact that about 20 years into the epidemic millions of young people know little about STDs/HIV. It is thus essential that the knowledge and attitudes of this epidemic among youths should be an issue that secondary schools located within the country must take seriously because her principal clients according to Kelly (2002) are students most of whom are in the 13-20 year old age group. Badcock-Walters and Whiteside (2000), posit that the pandemic's impacts on education is not a single event in the history of Africa, but a factor that will condition and constrain the delivery, quality and output of education for a very long time to come.

Adolescents especially in secondary schools in Nigeria, are the group at high risk in the rapidly growth of STDs and HIV pandemic, and there is the need to broaden their knowledge and attitude towards these infections. Several studies have documented the high sexual activities and risky behaviours among adolescents in most parts of the world, thus putting them at high risk of contracting the HIV infection and STDs complications. During this time, they try out experiences for the first time and this is often the time for sexual experimentation by some youths. It is however, accompanied by lack of knowledge and skill to make healthy choices. The provision of effective healthcare facilities will go a long way to fashion acceptable preventive measures and treatment of HIV and STDs that will assist adolescents as well as favour norms and cultures as much as possible.

Rohleder (2009) observed that studies have shown that increasing communication between young adolescents and the adults in their lives delays the age at which adolescents start having sex and increase their use of condoms when they start. Also, UNFPA (2006) aptly captured the inadequate knowledge of the adolescents irrespective of their home type when it observed that often young adults do not understand how to protect themselves against sexually transmitted diseases. These findings were in line with that of Okoro (2005), Piotrow, Rimon, Merritt and Saffitz (2003) on the importance of communication between the teens and their families, that communication through exposure to HIV/AIDS prevention messages will change the adolescents high risk behaviour.

Sekirime, Tamale, JLule, and Mangen in their study Knowledge, attitude and practice about sexually transmitted diseases among university students of kampala in year 2001 found that more female than male students got information from their parents, while more male than female students had their information from previous sexual intercourse because of their explorative nature. News medical (2012) also observed that most times females do not know that they are infected with an STD until they start showing symptoms of the disease unlike male whose 
symptoms which appears quicker. The findings of UNFPA (2006) further confirmed this when it observed that evidence suggest that adolescents female constitute the sex and age group most susceptible to STDs including HIV infection, and that young women are physiologically more vulnerable to STDs and also more vulnerable to coercion, while the study of Zeeb, Spallek, and Zeeb (2011) showed that school-based health centers see the largest proportion of teenage males than females.

Birdthistle and Whiteman (2012) reported that schools have a role to play in facilitating the access of young people to necessary reproductive health services and to link education and services so that students may bridge knowledge and attitude with action, and that schools can work to enhance access to services within the school as well as referral to external health system. Also, Dotata and Ross (2010) in their study affirmed that school is where most HIV and sexuality education programme are delivered, so children who are kept out of school are simply unreached by them. However, few studies if at have ever tried to look at the effect of school type on students' attitudes and knowledge on regular heath care, rather most studies looked at it as homogenous whole.

It is against this backdrop that this study assessed the efforts of the adolescents in availing themselves to regular healthcare as a means of improving HIV and STD testing and treatment. It also looked at status of the secondary school students with respect to their exposure to HIV and STDs prevention messages. It investigated some social and personality factor: school type (public or private), family background (single parents or married parents), knowledge and attitudinal disposition and risk reduction behaviours /practices to HIV and STD testing and treatment among secondary students in Urban Secondary Schools in Ibadan North Local Government of Oyo State, Nigeria.

\section{Hypotheses}

The following hypotheses were raised in a null form:

1) There is no significant relationship between the knowledge and attitude of secondary school students on regular healthcare as a factor in improving HIV/ STDs testing and treatment.

2) There is no significant school type difference in the knowledge of regular healthcare as a factor in the testing and treatment of HIV/ STDs among secondary schools' students.

3) There is no significant school type difference in the attitude of secondary schools' students toward regular healthcare as a factor in the testing and treatment of HIV/ STDs.

4) There is no significant gender difference in the knowledge and attitude of secondary schools students towards regular healthcare as a factor in improving HIV/STDs testing and treatment.

5) There is no significant family structure difference in the knowledge and attitude of secondary schools students towards regular healthcare as a factor in improving HIV/STDs testing and treatment.

\section{Methodology}

\subsection{Research Design}

The study adopted a descriptive survey research of an ex-post facto type. The investigators examined the relationship between the independent variables (knowledge, attitude, gender, family type and school type) and dependent variable (HIV/STD treatment and testing).

\subsection{Population}

The target population for the study comprised all the students in the four selected secondary schools in Ibadan North Local Government Areas of Oyo State, Nigeria.

\subsection{Sample/Sampling Procedure}

A multi-stage sampling technique was adopted for the study. First, stratified random sampling was applied in assigning the secondary students to two different strata based on institutional ownership- government owned and private owned. Second, simple random sampling was used in selecting four secondary schools: two from each stratum to ensure adequate representation. Third, simple random sampling was used to pick fifty-five respondents from each selected secondary school, making a total number of 220 respondents in all.

\subsection{Instrument}

A twenty-eight self-developed questionnaire tagged "Adolescent Knowledge and Attitude Scale (AKAS)". The instrument was designed on a 4-point Likert rating scale ranging from strongly agree to strongly disagree. To establish the reliability of the instrument, a test-re-test was conducted using a group of 30 respondents from a secondary school that did not form part of the sample. The Cronbach's coefficient of alpha was computed and 
this yielded reliability co-efficiency (r) of 0.89 . The instrument was therefore deemed highly reliable and good enough for use for the present study.

\subsection{Data Analysis}

The data collected through the questionnaire was analyzed, using both descriptive statistics (frequency counts and percentages) inferential statistics (T-test, and Pearson Product Moment Correlation) significant at .05 alpha level.

\section{Results}

Preliminary Results

Table 1. Participants' demographic results

\begin{tabular}{lllll}
\hline SN & Variable & & Frequency & $\mathbf{\%}$ \\
\hline 1 & Gender & Female & 125 & 56.8 \\
& & Male & 95 & 43.2 \\
2 & \multirow{3}{*}{ School } & Private & 110 & 50.0 \\
& & Public & 110 & 50.0 \\
3 & Class & JSS & 123 & 55.9 \\
& & SSS & 97 & 44.1 \\
4 & Age & $10-14$ & 137 & 62.3 \\
& & $15-20$ & 83 & 37.7 \\
5 & \multirow{2}{*}{ Family Type } & Single parenting & 31 & 14.1 \\
& & Double parenting & 189 & 85.9 \\
\hline
\end{tabular}

The participants' demographic results revealed that $125(56.8 \%)$ of the sampled population were female while the remaining $95(43.2 \%)$ were male respondents. Students from private secondary schools represented in this study were $50.0 \%(110)$ and $50.0 \%$ (110) were from public schools. One hundred and twenty-three $(123 ; 55.9 \%)$ were in junior classes, while the remaining ninety-seven $(97 ; 44.1 \%)$ were in senior classes. Respondents within the age bracket of 10 and 14years of age were $137(62.3 \%)$ while those between 15 and 20 years were 83 $(37.7 \%)$. The Table revealed further that $31(14.1 \%)$ of the respondents were from single parenting family type while the remaining $189(85.9 \%)$ were from double parenting type of family.

Table 2. Table showing the relationship between students' knowledge and attitude to regular healthcare on the testing and treatment of HIV/STDs

\begin{tabular}{ccccccc}
\hline \multicolumn{1}{c}{ Variable } & Mean & Std. Dev. & $\mathrm{N}$ & $\mathrm{R}$ & $\mathrm{P}$ & Remark \\
\hline Knowledge of Healthcare & 20.4227 & 3.6936 & & & & \\
Attitude of Healthcare & & & 220 & $.167^{*}$ & .013 & Sig. \\
\hline
\end{tabular}

*Significant at .05 alpha level

It is shown in the above table that there was a significant relationship between students' knowledge and attitude to regular healthcare on the testing and treatment of HIV/STDs $\left(r=.167^{*}, \mathrm{~N}=220, \mathrm{P}<.05\right)$. Therefore, the earlier stated null hypothesis of no significant relationship between knowledge and attitude of secondary students on regular healthcare as a factor in improving HIV/STDs testing and treatment is rejected. 
Table 3. T-test comparison of private and public schools students' knowledge of regular healthcare in improving HIV/STDs testing and treatment

\begin{tabular}{llllllll}
\hline $\begin{array}{l}\text { Knowledge of HIV/STDs Testing } \\
\text { and Treatment }\end{array}$ & $\mathrm{N}$ & Mean & Std. Dev. & t-crit. & t-cal. & df & P \\
\hline Private Schools & 110 & 28.0545 & 5.5220 & & & & \\
& & & & 1.96 & 3.065 & 218 & .002 \\
Public Schools & 110 & 30.3636 & 5.6532 & & & & \\
\hline
\end{tabular}

*Significant at .05 alpha level

The results in Table 3 above showed that there is a significant difference in the knowledge of regular healthcare as a factor in the testing and treatment of HIV/ STDs among private and public secondary schools' students $($ Crit- $\mathrm{t}=1.96$, Cal. $\mathrm{t}=3.065, \mathrm{DF}=218, \mathrm{P}<.05)$. Thus, the earlier stated hypothesis was not sustained.

Table 4. T-test comparison of private and public schools' attitude towards regular healthcare in improving HIV/STDs testing and treatment

\begin{tabular}{llllllll}
\hline $\begin{array}{l}\text { Attitude to HIV/STDs Testing and } \\
\text { Treatment }\end{array}$ & $\mathrm{N}$ & Mean & Std. Dev. & Crit-t & Cal-t. & df & P \\
\hline Private Schools & 110 & 28.3364 & 7.2013 & & & & \\
& & & & 1.96 & 1.096 & 218 & .274 \\
Public Schools & 110 & 29.4182 & 7.4420 & & & & \\
\hline
\end{tabular}

**Not Significant at .05 alpha level

The above Table 4 showed no significant difference in the attitude towards regular healthcare as a factor in improving HIV/STDs testing and treatment between private and public schools' students $(\mathrm{Crit}-\mathrm{t}=1.96$, Cal.t $=$ $1.096, \mathrm{df}=218, \mathrm{P}<.05)$. The results failed to negate the hypothesis that stated there is no significant school type difference in the attitude of secondary schools' students toward regular healthcare as a factor in the testing and treatment of HIV/ STDs. Therefore, the earlier stated hypothesis was retained.

Table 5. T-test analysis showing gender difference in knowledge of regular healthcare in improving HIV/STDs testing and treatment

\begin{tabular}{llllllll}
\hline & Gender & $\mathrm{N}$ & Mean & $\begin{array}{l}\text { Std. } \\
\text { Deviation }\end{array}$ & $\begin{array}{l}\text { Mean } \\
\text { Difference }\end{array}$ & df & T-calculated \\
\hline Knowledge & male & 95 & 29.442 & 4.672 & 0.410 & 218 & $0.528^{*}$ \\
& female & 125 & 29.032 & 6.375 & & & \\
Attitude & male & 95 & 30.190 & 7.011 & 2.310 & 218 & $2.234^{* *}$ \\
& female & 125 & 27.880 & 7.430 & & & \\
\hline
\end{tabular}

*Not significant; ${ }^{* *}$ Significant at .05 alpha level

The results presented in Table 5 revealed that the obtained value of $t$ is .528 for the gender difference in knowledge of regular healthcare in improving HIV/STDs testing and treatment among secondary school students which is less than the $\mathrm{t}$ - critical value of 1.96 at 218 degree of freedom and 0.05 level of significance $(\mathrm{t}$-cal $=.528, \mathrm{t}$-crit $=$ $1.960, \mathrm{P}=.05$ ). This implies that there is a significant gender difference in the knowledge of male and female students on healthcare as a factor in the testing and treatment of HIV/STD. On the other hand, significant gender difference was observed in students' attitude toward regular healthcare in improving HIV/STDs testing and treatment $(\mathrm{t}$-cal $=2.310, \mathrm{t}$-crit $=1.960, \mathrm{P}=.05)$. 
Table 6. T-test analysis showing family structure difference in knowledge of regular healthcare in improving HIV/STDs testing and treatment

\begin{tabular}{llllllll}
\hline & $\begin{array}{l}\text { Family } \\
\text { structure }\end{array}$ & $\mathrm{N}$ & Mean & $\begin{array}{l}\text { Std. } \\
\text { Deviation }\end{array}$ & $\begin{array}{l}\text { Mean } \\
\text { Difference }\end{array}$ & df & T-calculated \\
\hline Knowledge & Single & 31 & 29.516 & 5.893 & 0.357 & 218 & $0.323^{*}$ \\
& Intact & 189 & 29.159 & 5.675 & & & \\
Attitude & Single & 31 & 29.194 & 8.581 & 1.457 & 218 & $0.259^{*}$ \\
& Intact & 189 & 28.825 & 7.124 & & & \\
& & & & & & & \\
\end{tabular}

* Not significant at .05 alpha level

The above table showed that there was no significant difference in the knowledge (Crit- $t=1.96$, Cal.t $=0.323$, $\mathrm{DF}=218, \mathrm{P}>.05$ level $)$ and attitude $(\mathrm{Crit}-\mathrm{t}=1.96, \mathrm{Cal} . \mathrm{t}=0.259, \mathrm{DF}=218, \mathrm{P}>.05)$ towards HIV/STDs Testing and Treatment of single parenting and intact home (both parents) respondents.

\section{Discussion}

Results of the relationship between students' knowledge and attitude to regular healthcare on the testing and treatment of HIV/STDs indicated a significant relationship between knowledge and attitude. The implication of the finding is that because the students lack the essential and adequate information about healthcare provision to HIV/STDs testing and treatment, their attitude towards these dreaded infections is not favourable. The outcome of this finding corroborates that of Birdthistle and Whiteman (2012) that schools have a role to play in facilitating the access of young people to necessary reproductive health services and to link education and services so that students may bridge knowledge and attitude with action, and that schools can work to enhance access to services within the school as well as referral to external health system. The findings of Dotata and Ross (2010) further substantiated this, when they observed that school is where most HIV and sexuality education programme are delivered, so children who are kept out of school are simply unreached by them.

On the difference in the knowledge of regular healthcare as a factor in the testing and treatment of HIV/ STDs among private and public secondary schools' students, significant difference was observed. Going through the mean scores, it could be deduced that students in private secondary schools are less aware of regular healthcare as a factor in HIV/STDs testing and treatment compared to their counterparts in public secondary schools. The lesser level of knowledge observed in this study lends credence to Odivwri (2004) report that there is a general belief that not much of awareness (preventive messages) has been created in the society. So, some people do not really feel the effect of the campaign despite National Action Committee on AIDS (NANA) effort to radio jingles on 60 stations currently just as it runs campaigns on 19 TV stations nationwide with printed leaflets and bill boards. Alutu (2002) further asserted that 20 years into the epidemic, millions of young people know little about HIV/AIDS. The justification of more public secondary school students being aware than private secondary students tallies with the findings of TIP (2002) that due to their explorative nature, they were able to target their colleagues for information than if an outsider were to come in to teach them about HIV/AIDS. The study therefore revealed that their exposure to prevention messages was influenced by environmental factors. Kelly (2001) further asserted that they are predominantly health centered in that they look in mostly for information, a medium of prevention, some health treatment, and some Counselling which is not comprehensive in either scope or coverage. For it to be comprehensive, it has to be multi-sectorial, multi-disciplinary and multi-dimensional.

The result of no significant difference in the attitude towards regular healthcare as a factor in improving HIV/STDs testing and treatment between private and public schools' students, by implications show that although students from public secondary schools seem to be more knowledgeable than their counterparts in the private school because of their explorative tendencies, yet their attitude towards healthcare does not correspond with their level of awareness. No wonder Kelly (2001) noted that whereas knowledge on methods of prevention was high, it was not followed by appropriate behavioural patterns. This finding is further supported with the findings of Sekirine et al. (2000), that the level of knowledge about STDs and their prevention is not matched by sexual behavioural patterns.

No gender difference was found in the knowledge of regular healthcare in improving HIV/STDs testing and treatment among secondary school students. This no difference tallies with the study of Sekirime et al. (2001), 
who observed that more female than male students got information from their parents, while more male than female students had their information from previous sexual intercourse because of their explorative nature. However, the aspect that measures gender difference in attitude toward regular healthcare in improving HIV/STDs testing and treatment among secondary school students revealed that male students had an average mean score of 30.190 while their female counterparts had a mean score of 27.880 . It could be deduced that because the male students are more explorative in their sexual dealings than their female counterpart, they have better attitude towards healthcare. This is substantiated by F. Zeeb, Spallek, and H. Zeeb (2011), whose research findings showed that school-based health centers see the largest proportion of teenage males. Also, male better attitude to STD than the female may be attributed female's biological makeups which exposes and hide these infections than their male counterpart. Thus, News medical (2012) observed that most times females do not know that they are infected with an STD until they start showing symptoms of the disease unlike male whose symptoms which appears quicker. The findings of UNFPA (2006) further confirmed this when it observed that evidence suggest that adolescents women constitute the sex and age group most susceptible to STDs including HIV infection, and that young women are physiologically more vulnerable to STDs and also more vulnerable to coercion.

The hypothesis on the difference in knowledge and attitude based on family structure no significant difference in the knowledge and attitude towards HIV/STDs Testing and Treatment. This means that family structure of the students does not necessarily affect their knowledge of healthcare as a factor in improving their HIV/STD testing and treatment. By implication it means that irrespective of students' family structure, adolescents' are not well exposed to sexuality education, especially on the need to regular healthcare as a prevention strategy. The assertion of Rohleder (2009) supported this when they observed that studies have shown that increasing communication between young adolescents and the adults in their lives delays the age at which adolescents start having sex and increase their use of condoms when they start. Also, UNFPA (2006) aptly captured the inadequate knowledge of the adolescents irrespective of their home type when it observed that often young adults do not understand how to protect themselves against sexually transmitted diseases. These findings corroborate that of Okoro (2005), Piotrow, Rimon, Merritt, and Saffitz (2003) on the importance of communication between the teens and their families, that communication through exposure to HIV/AIDS prevention messages will change the adolescents high risk behaviour.

\section{Conclusion}

Based on the result obtained from the analysis of the data, it was concluded that there is need for adolescents to avail themselves for regular healthcare. Thus, they need to broaden their level of awareness, knowledge and attitude towards regular healthcare, by visiting health centers to test their status on HIV/STDs and ensure timely treatment if found positive, so as not only to curb the transmission of the infection, but also to possibly avert its grievous consequences.

\section{Recommendations}

While the majority of secondary students had heard about HIV/STDs, their knowledge was inadequate. Thus, schools have a role to play in facilitating the access of young people to necessary reproductive health services and to link education and services so that students may bridge knowledge and attitudes with action. The school can achieve this by establishing school-based health centers where such services can be rendered or by referring them to local health and counselling services requiring little financial expenditure.

It was also discovered that parents play a crucial role in the education of the adolescence about sexual matters. Parents can therefore contribute to improve reproductive health among adolescents by increasing their knowledge and attitude to regular healthcare, as way of improving the testing and treatment of HIV/STDs. This can be achieved when parents talk with their teens about their sexual health, their dating, sexual behavior, abstinence and contraception, STDs, HIV and having healthy relationship.

Government needs to tackle the problem of the health sector holistically through law and administrative reforms, proper funding, staffing, equipping, welfare and implementation of health laws and regulations. It is high time we also place premium on preventive medicine by embarking on civic education of the adolescence on how to live healthy lifestyle. This can be done by providing education, treatment and effective cure to adolescents that are at increased risks of infection and transmitting infection.

\section{References}

AIDS info. (2009). National Institute of Health. Retrieved April 2013, from http://www.Aidsinfo.nih.gov.en 
Alutu, A. N. G (2003). In F. Ouekwe, M. F. E Oiejomaoh, \& D. Donaonkar (Eds.), Psychosocial Dimension of people living with HIV/AIDS in Africa: Care and support. Trends in HIV/AIDS care. Mindex Publishing.

Badcock-Walters, P., \& Alan, W. (2000). HIV/AIDS and Development in the Education Sector (Unpublished paper. Health Economics and HIV/AIDS Research Division, University of Natal).

Birdthistle, I., \& Whiteman, C. N. (2012). Reproductive health program for young adults: School-based programs. Newton Education Development Center, Inc.

De Kock, K. M., Ekpini, E., \& Gnaore, E. (1994). The public health implications of AIDS research in Africa. Journal of the American Medical Association, 6(272), 481-486. http://dx.doi.org/10.1001/jama.1994.03520060081036

Dotata, S., \& Ross, K. (2010). How successful are HIV-AIDS prevention education programmes. SACMEQ Policy/Issue Series no.3

Earl, D. (1995). Re-examination of the paradigm of HIV risk reduction in adolescents. Journal of the American Osteopathic Association, 95(12), 725-728.

Federal Ministry of Health Nigeria (2008). National HIV/Syphilis sero-prevalence sentinel survey, process and findings. National AIDS/STDs Control Programme (NASCP).

Feyistan, B., \& Pebley, A. R. (1989). Premarital sexuality in urban Nigeria. studies on family planning, 20(6), 343-354. http://dx.doi.org/10.2307/1966437

Kelly, M. J. (2000). Standing education on its heed: Aspects of schooling in a world with HIV/AIDS. Current issues in Comparative Education, 3(1).

Kelly, M. J. (2001). Education challenging the challenger: Understanding and expanding the response of universities in Africa to HIV/AIDS. Lusaka: Association for the Development of Education in Africa.

Laga et al. (1993). Non-ulcerative sexually transmitted diseases as risk factors for HIV transmission in women: Results from a cohort study. AIDS, 7(1), 95-102. http://dx.doi.org/10.1097/00002030-199301000-00015

News Medical. (2012). What is an Std. Retrieved from http://googleads.g.doubleclicknet

Okoro, C. A. (2005). Environmental and personality factors influencing the exposure to HIV/AIDS prevention messages among university student in South Western Nigeria (Unpublished PhD thesis).

Panchaud, C., Susheela, S., Feivelson, D., \& Darroch, J. E. (2000). Sexually transmitted diseases among adolescents in developed countries. Fam plann perspective, 32, 24-32. http://dx.doi.org/10.2307/2648145

Population Reference Bureau. (2000). The World's Youth 2000: Data Sheet. Washington, D C: The Bureau.

Prejean, J., Song R., Hernandez, A., Ziebell, R., Green, T., Walker, F. ... Hall, H. I. (2011). Estimated HIV incidence in the United States, 2006-2009. PLOS ONE, 6(8). http://dx.doi.org/10.1371/journal.pone.0017502

Rohleder, P. (2009). HIV/AIDS and disability in Southern Africa: A review of relevant literature. Disability and rehabilitation, 3(1), 51-59. http://dx.doi.org/10.1080/09638280802280585

Sekirime, W. K., Tamale, J., Lule, J. C., \& Mangen, F. W. (2001). Knowledge, attitude and practice about sexually transmitted diseases among university students of kampala. African Health Sciences, 1(1).

UNAIDS. (1999). Listen, Learn, Live! World AIDS Campaign with children and young people. Facts and figure, Geneva.

UNFPA. (2005). The promise of equality: gender equality, reproductive health and the millennium goals. In Technical Reports. United Nations Population Fund, New York.

UNFPA. (2006). Preventing of HIV infection. Global youth's partners. Advocating for increased access by young people to information, education and services in the areas of HIV prevention.

Weinstock, H., Berman, S., \& Cates, W. (2004). Sexually transmitted diseases among American youth: Incidence and prevalence estimates. Perspectives on Sexual and Reproductive Health, 36(1), 6-10.

WHO/UNAIDS. (2011). Sexually transmitted diseases: Policies and principles for prevention and care preventism.

Zeeb, F. N. S., Spallek, L., \& Zeeb, H. (2011). Awareness and knowledge of sexually transmitted diseases (STDs) among school going adolescents in Europe: A systematic review of published literature. Germany BMC Public Health. 


\section{Copyrights}

Copyright for this article is retained by the author(s), with first publication rights granted to the journal.

This is an open-access article distributed under the terms and conditions of the Creative Commons Attribution license (http://creativecommons.org/licenses/by/3.0/). 